\title{
SURGICAL TREATMENT AND POST-OPERATIVE HÆMODYNAMIC STUDIES IN HYPERTROPHIC OBSTRUCTIVE CARDIOMYOPATHY
}

\author{
BY \\ H. H. BENTALL, W. P. CLELAND, C. M. OAKLEY*, P. M. SHAH, $\dagger$ \\ R. E. STEINER, AND J. F. GOODWIN \\ From the Departments of Medicine (Clinical Cardiology), Surgery, and Radiodiagnosis, \\ Postgraduate Medical School of London \\ Received November 24, 1964
}

Since the original description by Brock of functional obstruction of the left ventricle (Brock, 1957) and the pathological appearances described by Teare (1958), many reports of the surgical treatment of hypertrophic obstructive cardiomyopathy (muscular hypertrophic subaortic stenosis) have appeared (Goodwin et al., 1960; Braunwald et al., 1960; Kirklin and Ellis, 1961; Morrow and Brockenbrough, 1961; Wigle, Heimbecker, and Gunton, 1962; Wigle, Chrysohou, and Bigelow, 1963; Cohen et al., 1964; Dobell and Scott, 1964; Kittle, Reed, and Crockett, 1964; Trimble et al., 1964; Cleland, 1964a, b; Bentall, 1964; Swan, 1964).

The present paper reports our experience with 12 patients treated surgically between the years 1958 and 1963 and amplifies our original reports (Goodwin et al., 1960; Cohen et al., 1964; Cleland, 1964a, b; Bentall, 1964) by means of post-operative hæmodynamic studies.

\section{Patients AND Methods}

Operations were done on 12 patients, 6 male and 6 female, whose ages ranged from 6 to 55 years. All complained of angina on effort, dyspnœa, dizziness, or syncope, or a combination of these symptoms.

The characteristic physical signs consisting of a jerky arterial pulse and an ejection murmur of late onset maximal at the left sternal edge were present in all, while an audible or palpable atrial sound at the apex occurred in 4 patients; a double systolic thrust due either to a palpable atrial sound or to a double systolic thrust was found in 4 instances. The second heart sound was single or reversed in 8 patients and normal in 4. Signs of right ventricular involvement consisting of a tricuspid diastolic murmur or exaggerated ' $a$ ' wave in the jugular venous pulse occurred in 5 patients.

The electrocardiogram showed left or combined ventricular hypertrophy, often with striking atrial enlargement and sometimes with splintering of the QRS complex in central chest leads, indicating hypertrophy of the septum. A characteristic pre-excitation pattern with a short $\mathbf{P}-\mathbf{R}$ interval and a delta wave was notable in 2 patients and complete or partial left bundle-branch block was present before operation in 2 patients (Fig. 1 and 2) (Hollister and Goodwin, 1963).

The diagnosis was confirmed by retrograde left ventricular angiocardiography which showed the usual appearances of massive ventricular hypertrophy and narrowing and irregularity of the cavity of the left ventricle, often with associated mitral incompetence (Braunwald et al., 1960; Cohen et al., 1964) (Fig. 3A and B).

Left ventricular systolic pressures were increased in all but one patient (E.G.). The gradients recorded at rest varied from 25 to $130 \mathrm{~mm}$. $\mathrm{Hg}$ in 11 . In the one patient who had no resting gradient at the time

* Supported by a grant from the British Heart Foundation.

† Supported by a grant from the International Cardiology Foundation. 


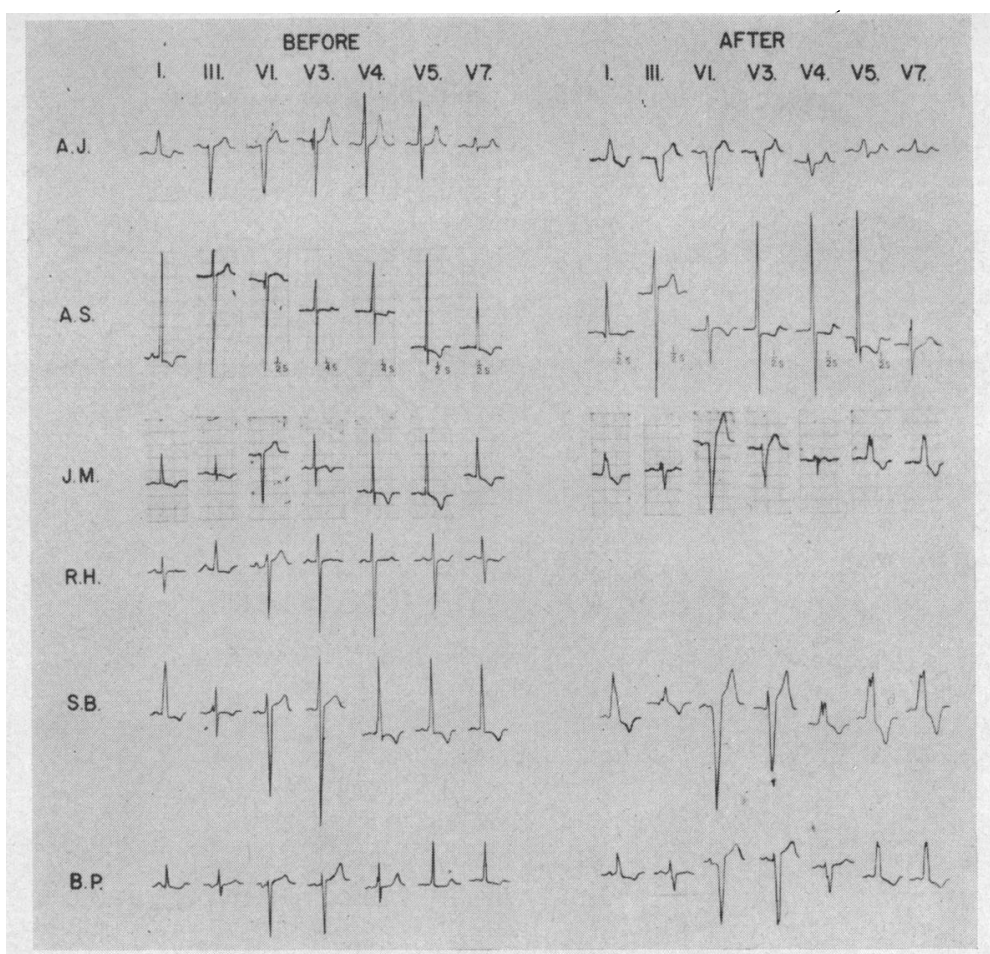

FIG. 1.-Selected leads from electrocardiograms in 6 patients before and after operation (see text). $\left(\frac{1}{2} \mathrm{~s}=\frac{1}{2}\right.$ sensitivity.)

BEFORE

AFTER

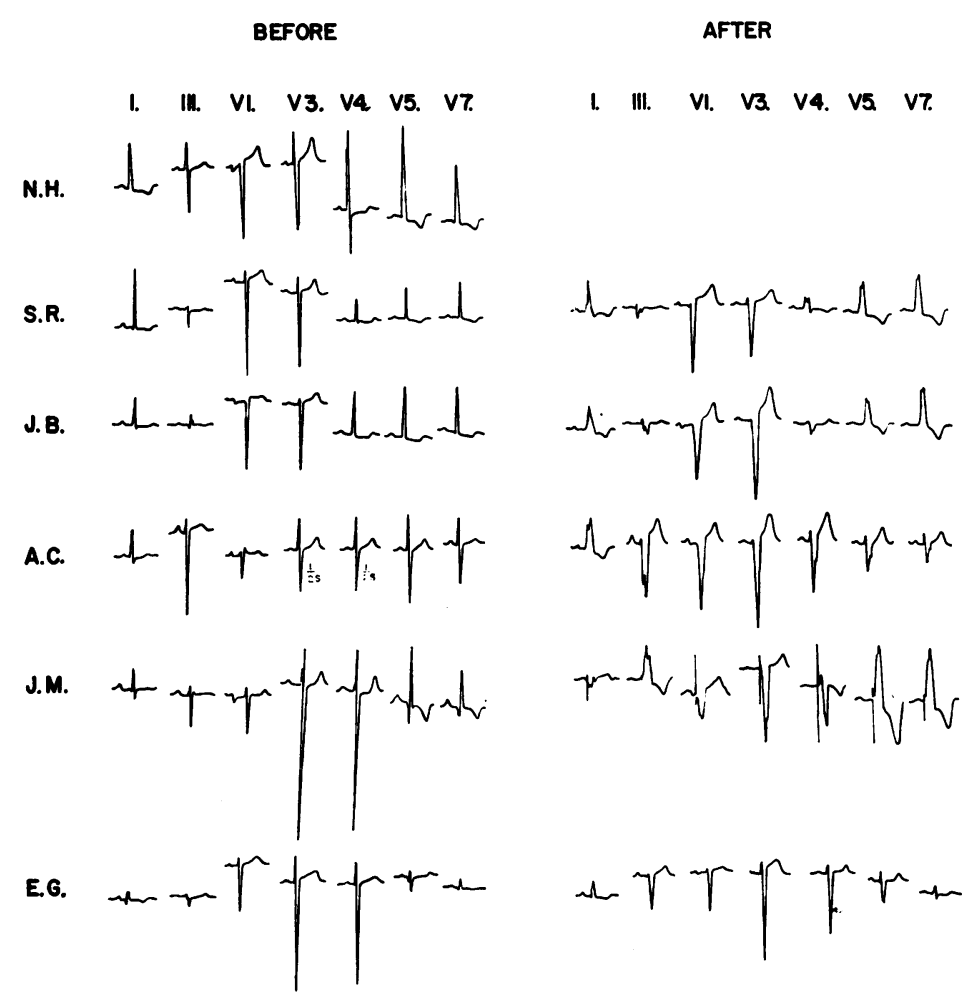

FIG. 2.-Selected leads from electrocardiograms in the remaining 6 patients before and after operation (see text). (Case A.C., leads V3 and V4 are at half sensitivity before operation.) 

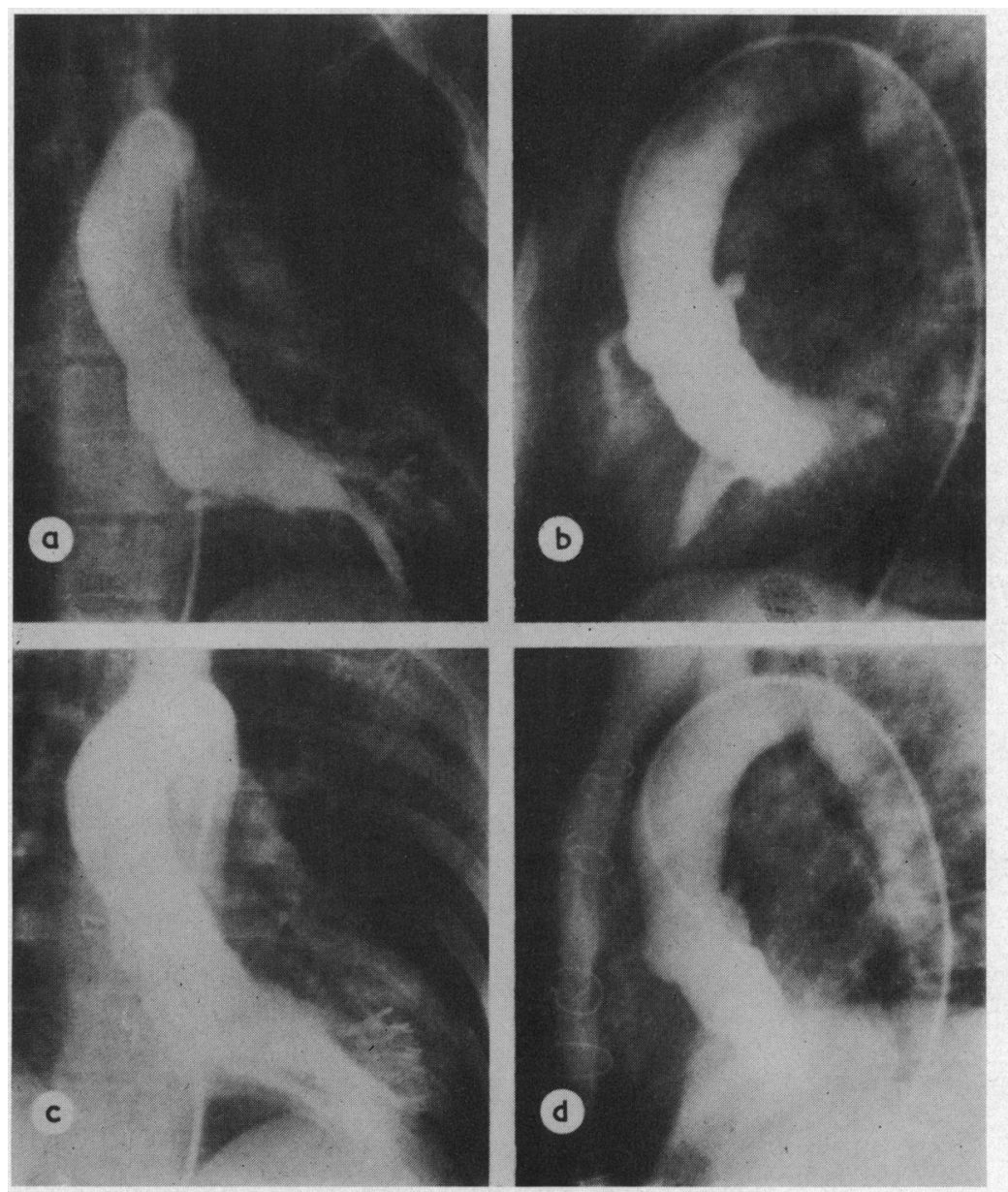

of study there was a gradient of up to $103 \mathrm{~mm}$. $\mathrm{Hg}$ after ventricular ectopic contractions, while isoprenaline provoked a gradient of $73 \mathrm{~mm}$. $\mathrm{Hg}$ (Table I). As would be expected in this condition, the gradients measured at operation often differed from those at catheterization (Table II).

Indications for Operation. The following criteria were fulfilled in every patient; first, the presence of disabling or dangerous symptoms of obstruction to left ventricular outflow such as dizziness, syncope, or angina; second, physical signs of persistent or episodic obstruction as shown by the characteristic murmur and arterial pulse; third, the demonstration of an outflow tract gradient either at rest, following an ectopic beat, or on provocation with isoprenaline; and fourthly, confirmation of the diagnosis by angiocardiography. Dyspnœa alone was regarded as an indication in only one patient (J.Mo.) because of the extreme severity of the disease judged clinically and radiologically.

The Operation. All the operations were performed under cardiopulmonary bypass, directed by Dr. Denis Melrose, with hypothermic perfusion into the root of the aorta until the heart temperature reached $15^{\circ} \mathrm{C}$. An oblique incision was made in the aorta and the interior of the ventricle was exposed using a modified nasal speculum. Hypertrophied muscle bands on the septum 2-3 cm. below the valve were seen 
TABLE I

Pre-Operative Symptoms, Pressure Gradients, and Family History

\begin{tabular}{|c|c|c|c|c|}
\hline Patient & Age (yr.) & Symptoms & $\begin{array}{l}\text { Gradient between } \\
\text { left ventricle and } \\
\text { aorta }(\mathrm{mm} . \mathrm{Hg})\end{array}$ & Family history \\
\hline $\begin{array}{l}\text { A.J. } \\
\text { A.S. } \\
\text { J.Ma. } \\
\text { R.H. } \\
\text { S.B. } \\
\text { B.P. } \\
\text { N.H. } \\
\text { S.R. } \\
\text { J.B. } \\
\text { A.C. } \\
\text { J.M. } \\
\text { E.G. }\end{array}$ & $\begin{array}{r}47 \\
7 \\
55 \\
32 \\
19 \\
49 \\
48 \\
26 \\
37 \\
19 \\
13 \\
43\end{array}$ & $\begin{array}{l}\text { Syncope, dyspnœea, angina } \\
\text { Fatigue, angina } \\
\text { Dyspnœe, angina } \\
\text { Syncope, dyspnœa, angina } \\
\text { Syncope, dyspnœa, angina } \\
\text { Syncope, dyspnœa } \\
\text { Syncope, angina } \\
\text { Dyspnœa, angina } \\
\text { Syncope, dyspnœa } \\
\text { Dizziness } \\
\text { Dyspnœea } \\
\text { Syncope, dyspnœa }\end{array}$ & $\begin{array}{c}60 \\
\text { Not measured } \\
80 \\
60 \\
55 \\
85 \\
25 \\
90 \\
130 \\
60 \\
31 \\
0 \text { at rest } \\
73 \text { after isoprenaline }\end{array}$ & $\begin{array}{c}+? \\
+? \\
\text { Brother with syncope; sister with } \\
\text { hypertension } \\
+? \\
+? \\
0 \\
0 \\
+? \\
+? \\
2 \text { sibs died with proven HOCM } \\
+? \\
0\end{array}$ \\
\hline
\end{tabular}

HOCM = Hypertrophic obstructive cardiomyopathy.

$+?=$ History of heart disease of uncertain type, and/or sudden death.

TABLE II

Hamodynamic and ANGIOGRaphic Results of Operation for Hypertrophic Obstructive Cardiomyopathy

\begin{tabular}{|c|c|c|c|c|c|c|c|c|c|}
\hline \multirow[t]{2}{*}{$\begin{array}{l}\text { Patient, } \\
\text { age, and sex }\end{array}$} & & \multicolumn{3}{|c|}{$\begin{array}{l}\text { At catheterization } \\
(\mathrm{mm} . \mathrm{Hg})\end{array}$} & \multicolumn{2}{|c|}{$\begin{array}{l}\text { At operation } \\
(\mathrm{mm} . \mathrm{Hg})\end{array}$} & \multirow[t]{2}{*}{ LV angiogram } & \multirow[t]{2}{*}{$\begin{array}{l}\text { Re-studied: years } \\
\text { post-operatively }\end{array}$} & \multirow[t]{2}{*}{$\begin{array}{c}\text { Hæmodynamic } \\
\text { result }\end{array}$} \\
\hline & & LV & Gr. & LVED & LV & Gr. & & & \\
\hline $\begin{array}{l}\text { A.J., 42, M } \\
\text { A.S., 8, M } \\
\text { S.B., 19, F } \\
\text { B.P., 45, F } \\
\text { S.R., 25, F } \\
\text { J.B., 35, F } \\
\text { E.G., 43, M }\end{array}$ & $\begin{array}{l}\mathbf{B} \\
\mathbf{A} \\
\mathbf{B} \\
\mathbf{A} \\
\mathbf{B} \\
\mathbf{A} \\
\mathbf{B} \\
\mathbf{A} \\
\mathbf{B} \\
\mathbf{A} \\
\mathbf{A} \\
\mathbf{B} \\
\mathbf{A} \\
\mathbf{B} \\
\mathbf{A}\end{array}$ & $\begin{array}{l}155 \\
150 \\
120 \\
150 \\
100 \\
210 \\
125 \\
160 \\
170 \\
235 \\
140 \\
100 \\
150\end{array}$ & $\begin{array}{r}60 \\
15 \\
20 \\
55 \\
0 \\
90 \\
12 \\
50 \\
90 \\
120 \\
0 \\
10 \\
55\end{array}$ & $\begin{array}{l}30 \\
12 \\
25 \\
20 \\
12 \\
35 \\
20 \\
30 \\
25 \\
50 \\
15 \\
10 \\
15\end{array}$ & $\begin{array}{r}150 \\
135 \\
240 \\
220 \\
130 \\
100 \\
200 \\
90 \\
140 \\
95 \\
140 \\
120 \\
140 \\
95\end{array}$ & $\begin{array}{r}30 \\
25 \\
120 \\
80 \\
12 \\
0 \\
120 \\
10 \\
20 \\
0 \\
30 \\
20 \\
32 \\
5\end{array}$ & $\begin{array}{l}\text { Slight } \overline{\mathrm{MI}} \\
\text { Moderate MI } \\
\text { Moderate MI } \\
\text { No MI } \\
\text { Moderate MI } \\
\text { Slight MI } \\
\text { No MI } \\
\text { Considerable MI } \\
\text { Moderate MI } \\
\text { Slight MI } \\
\text { Slight MI }\end{array}$ & $\begin{array}{l}5 \\
4 \\
1 \frac{1}{2} \\
1 \frac{1}{2} \\
1 \\
1 \\
\frac{1}{2}\end{array}$ & $\begin{array}{c}\text { Excellent } \\
\text { Improved } \\
\text { Much improved } \\
\text { Excellent } \\
\text { Unchanged } \\
\text { Much improved } \\
\text { Unchanged }\end{array}$ \\
\hline
\end{tabular}

B, before operation; A, after operation; LV, left ventricular systolic pressure; Gr., gradient; LVED, left ventricular end-diastolic pressure; and MI, mitral incompetence.

in the majority. These were grasped with forceps and liberally excised using a long-handled knife, long scissors, or punch forceps. Considerable quantities of muscle could often be removed from the septum but excision elsewhere was performed more cautiously (Bentall, 1964).

The region below the aortic valve holds many hazards for the surgeon. The aortic leaflet of the mitral valve lies below the left coronary cusp of the aortic valve. The membranous portion of the ventricular septum and the bundle of His are related to the commissure between the right and non-coronary cusps of the aortic valve, and the right atrium is in direct relation to the ventricular septum below the non-coronary cusp.

Thus, the chief dangers in the operation lie in damage to the mitral valve, conducting system, and ven- 
TABLE III

Operative Pressure Gradients and Findings Related to SubJective Results

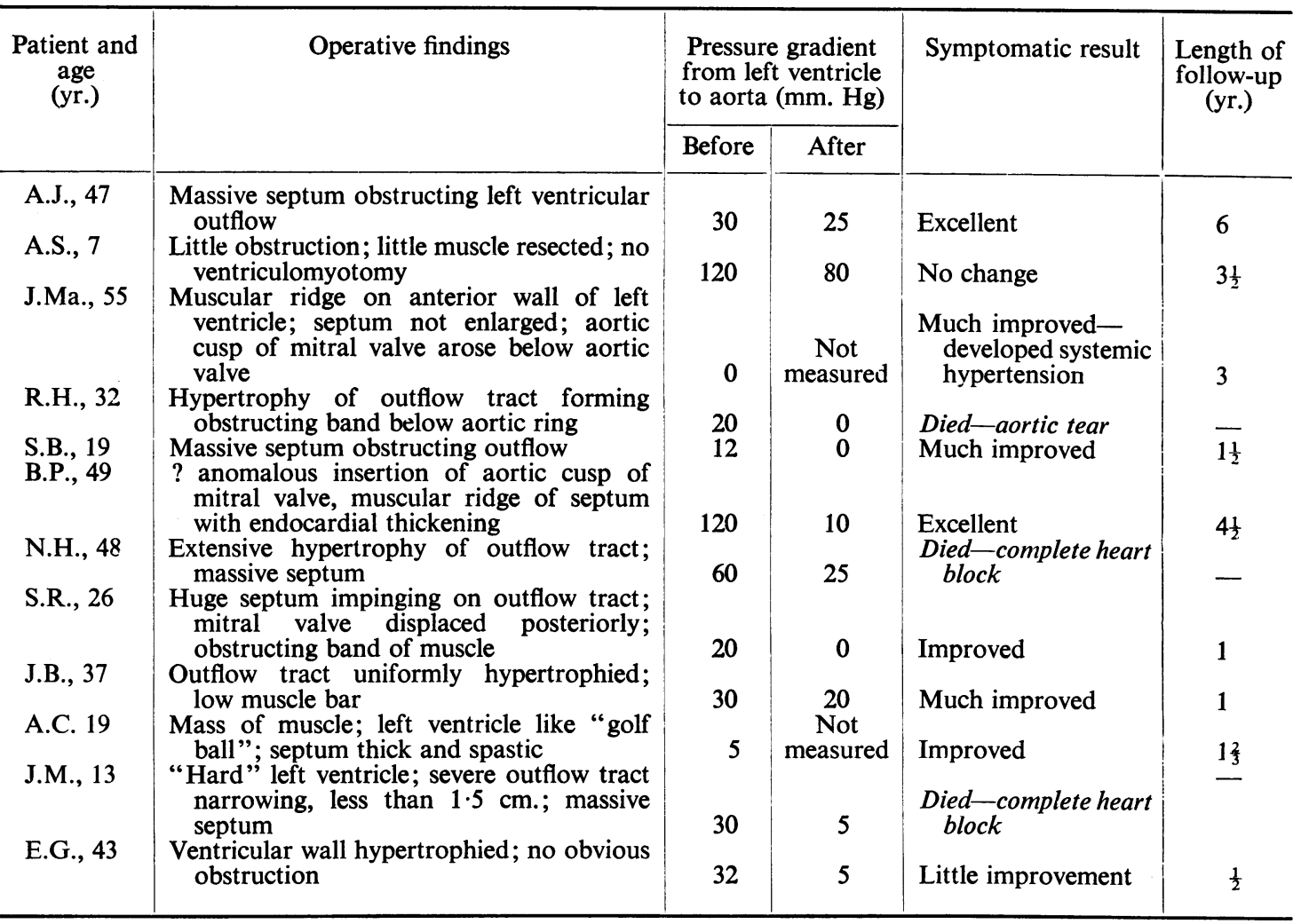

tricular septum, hazards that are illustrated by 2 of the 3 patients in the series who died, both from perforation of the ventricular septum and complete heart block.

Findings at Operation. In 9 patients there was massive hypertrophy of the septum with muscle masses obstructing the outflow tract of the left ventricle.

In the remaining 3 patients, the findings were somewhat different. Thus, in A.S. no obstruction was noted despite gross hypertrophy and despite a gradient before and after cardiotomy. This boy was second in the series, however, before the dynamic nature of the obstruction was understood, and the interior of the left ventricle was only inspected in the flaccid state after the heart had been arrested. The mitral valve in B.P. appeared to be abnormal, for the aortic leaflet seemed to occupy the posterior aspect of the outflow tract and the chordæ to originate from the posterior portion of the septum. Opposite the mitral leaflet there was a localized muscular ridge covered with thickened endocardium. It was thought that this might represent the abnormal insertion of the aortic cusp of the mitral valve described by Björk, Hultquist, and Lodin (1961), or alternatively displacement of the mitral valve by the abnormal muscle. In two other patients displacement of the aortic leaflet of the mitral valve was clearly secondary to muscular hypertrophy.

In G.G. no localized obstruction could be appreciated when the beating heart was examined, but the ventricular wall was grossly hypertrophied.

In 2 patients, A.C. and J.Mo., the muscle was described as hard or spastic (Table III).

\section{RESULTS}

Of the 12 patients, 9 survived the operation; 3 died, 2 from complete heart block associated with perforation of the membranous ventricular septum and one from an aortic tear (Tables II and III).

Symptomatic Improvement. Of the remaining 9 patients, only 8 were available for personal 


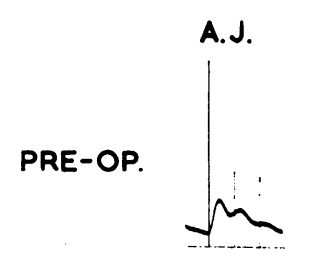

A.S.
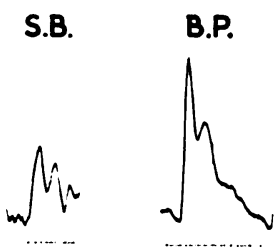

S.R.

J.B.

E.G.

POST-OP.
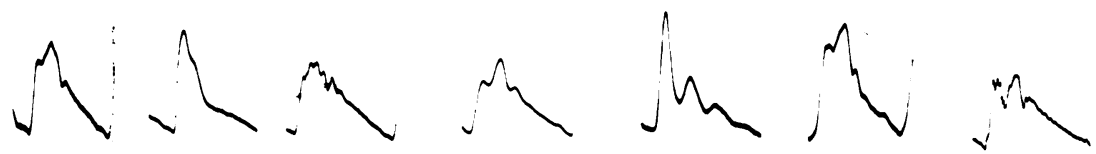

FIG. 4.-Aortic pressure pulses before and after operation for hypertrophic obstructive cardiomyopathy in 7 patients (no pre-operative record for patient A.S.).

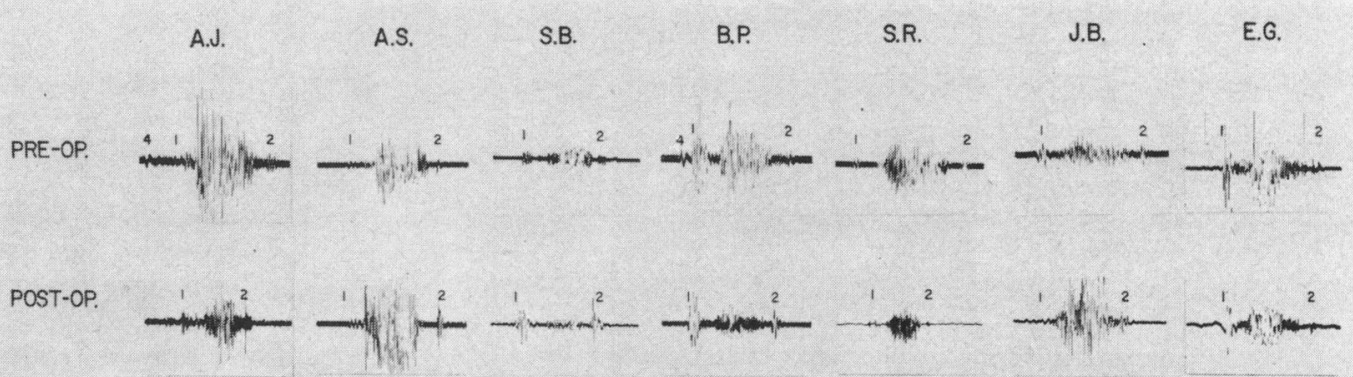

Fig. 5.-Phonocardiogram before and after operation in 7 patients (see text). $\quad 1=1$ st heart sound. $2=2$ nd heart sound. $4=$ atrial sound.

reassessment. The ninth, J.Ma., is overseas but keeps in touch with us by letter. There were 7 who showed symptomatic improvement, which was striking in 3 (A.J., B.Po., J.Ma.), considerable in 2 (S.B. and J.B.), and moderate in 2 (A.S. and A.C.). Two patients had little or no improvement (S.R. and E.G.). One patient (J.Ma.) whose improvement was very dramatic subsequently developed systemic hypertension but remains symptom free while his blood pressure is kept under moderate control.

Striking symptomatic improvement was regarded as loss of angina or syncope and marked relief of dyspnœa, with ability to lead a normal active life; considerable improvement as marked reduction in angina and abolition of syncopal or dizzy turns; and moderate improvement as reduction in angina, syncope, or dyspnoea, but persistent limitation of effort tolerance. The duration of follow-up has varied from six years to six months.

Objective Improvement. Clinical examination revealed a return of the arterial pulse to a more normal contour in 4 patients, and reduction in length and intensity of the systolic murmur in 4 patients, indicating relief of obstruction to left ventricular outflow (Fig. 4 and 5). In J.B., though the murmur was louder, it started earlier, indicating change in the specific contractile abnormality.

The electrocardiogram showed complete left bundle-branch block in 8 patients. Two patients (A.S. and E.G.) did not develop left bundle-branch block; in N.H. no electrocardiogram was obtained, but though the remaining patient (R.H.) died before an electrocardiogram could be recorded, the oscilloscope in the operating theatre recorded complete left bundle-branch block immediately after the operation on the left ventricle (Fig. 1 and 2).

Radiology. There was little change in the plain radiograph of the heart, but in no patient did the heart get smaller, and in 2 it increased in size. 
Post-operative left ventricular angiocardiography was carried out in 7 patients. No dramatic change in the configuration of the left ventricle was seen, but in 3 patients the mitral incompetence which had been present before operation had diminished or disappeared, and in one other patient the cavity of the left ventricle appeared larger (Fig. 3).

One patient (S.R.) who had had no relief of obstruction showed appreciable mitral incompetence after operation, but none before.

Hamodynamic Observations. Left ventricular and aortic pressures were recorded at retrograde arterial catheterization in 7 of the 9 surviving patients, 2 not being available for study. The studies were made from $5 \frac{1}{2}$ years to 6 months after operation (Table II) (Fig. 6). In one patient, the child (A.S.), since no preoperative hæmodynamic studies had been done, the post-operative catheter pressures were compared with the operating theatre pressures recorded before ventriculomyotomy.

In 5 patients the left ventricular outflow tract gradient was considerably reduced, and in 2 (S.R. and E.G.) the gradient had increased. In all except one patient (E.G.) the left ventricular end-diastolic pressure was lower than before the operation, possibly indicating improvement in function.

The changes in gradients and objective signs did not always harmonize with the sympto-

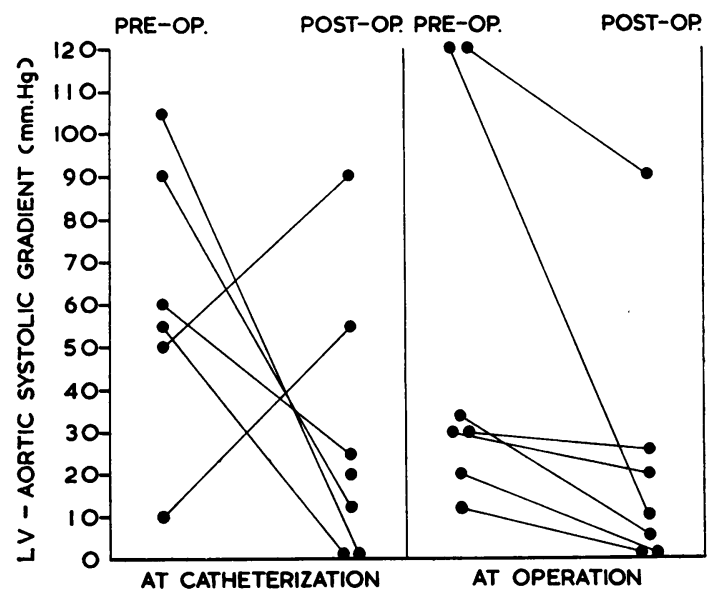

FIG. 6.-Left ventricular outflow tract systolic gradients in 7 patients before and after operation for hypertrophic obstructive cardiomyopathy.

matic improvement, and this was most striking in S.R., who experienced considerable relief of angina and dyspnœa, but whose jugular venous pressure rose after operation and whose signs of obstruction were not greatly altered. The post-operative left ventricular outflow tract gradient varied from 35 to $90 \mathrm{~mm} . \mathrm{Hg}$, and the left ventricular angiogram showed appreciable mitral incompetence where none had been seen before operation. By contrast, S.B. showed striking hæmodynamic improvement after operation, with reduction of the systolic gradient from $55 \mathrm{~mm}$. $\mathrm{Hg}$ before operation to zero after operation and with reduction of the end-diastolic pressure in the left ventricle from 20 to $12 \mathrm{~mm}$. Hg. Despite this, the physical signs, while indicating some reduction of obstruction, did not change to any marked extent, though the left ventricular angiocardiogram showed impressive loss of mitral incompetence after surgery.

The effect of drugs on the left ventricular outflow tract gradient was studied post-operatively in 4 patients (S.R., A.S., B.P., and E.G.), but no comparisons were possible since drugs had been employed in pre-operative studies in only one. In 2 (B.P. and A.S.) isoprenaline failed to increase the gradient in contrast to the response in untreated hypertrophic obstructive cardiomyopathy (Braunwald and Ebert, 1962). In S.R., who showed no objective benefit, the post-operative gradient was reduced by phenylephrine (Goodwin, 1964; Goodwin et al., 1964), but not by pronethalol.

The most disappointing results of drug studies were in E.G., in whom before operation a gradient occurred only after stimulation with isoprenaline. After operation a resting gradient of $55 \mathrm{~mm}$. $\mathrm{Hg}$ was found, and this increased to $95 \mathrm{~mm}$. $\mathrm{Hg}$ after isoprenaline but was reduced by pronethalol, which also increased the effective outflow orifice of the left ventricle (Table II).

The Patients Who Died. The first death (J.H.) followed an aortic tear which could not be repaired. Necropsy showed massive hypertrophy of the septum and left ventricle.

The second death (N.H.) was the result of complete heart block which occurred when the septum was accidentally perforated. The perforation was repaired and a pacemaker inserted to 
maintain a satisfactory ventricular rate, but despite this, an adequate cardiac output could not be maintained and she died five days after the operation, still in complete heart block. The heart at necropsy showed the typical appearance of hypertrophic obstructive cardiomyopathy.

The third death (J.M.) occurred one month after operation at which complete heart block had been induced following perforation of the membranous septum. The heart block was satisfactorily treated by electrical pacing, at first with external pulse generation, and then with an implanted pacemaker. Four days after the insertion of the internal pacemaker, she developed ventricular fibrillation. All attempts at resuscitation failed, including disconnexion of the pacemaker. The heart necropsy showed the typical appearance of the disease. These last 2 patients illustrate the importance of making the incision in the ventricular muscle mass strictly in line with the commissure between the left and right aortic cusps, for the gross overgrowth of the septal muscle can cause such distortion of the anatomy as to bring the membranous septum into the region normally occupied by muscle.

\section{Discussion}

The over-all results suggest that surgical treatment can be effective in this condition, the most striking example being the first patient to be operated upon (A.J.) in 1958. This patient and his operation have been reported by us previously (Goodwin et al., 1960), and he still maintains all his symptomatic, clinical, and hæmodynamic improvement six years later. The majority of the other patients have also shown improvement, but there has not been consistent agreement between symptoms, physical signs, and hæmodynamics. This is not surprising in view of the extreme variability of the obstruction in most patients.

Furthermore, it is not possible to say exactly how the operation produces benefit. There appear to be at least 4 possible mechanisms: first, the mechanical effect of removal of obstructing muscle; second, the creation of left bundle-branch block; third, interruption of abnormal sphincterlike activity by deep incision of the outflow tract muscle (ventriculomyotomy). Fourthly, pericardiotomy may allow an increase in ventricular size.

Mechanical relief is unlikely to play a major part, for the amount of muscle removed has usually been trivial compared to the gross hypertrophy present.

We originally thought that left bundle-branch block, by altering the pathway of left ventricular activation, was of fundamental importance. But unequivocal improvement following operation without the creation of complete left bundle-branch block has been reported by Wigle et al. (1962), though all his four cases showed evidence of some change in left ventricular conduction.

In our patients, complete left bundle-branch block occurred in all except A.S. and E.G., who showed the least improvement, but A.J. who had perhaps the best result of all had left bundlebranch block before operation, and we have one patient with left bundle-branch block amongst our unoperated group who has substantial outflow obstruction. It seems improbable, therefore, that left bundle-branch block is an essential criterion for improvement but it would be unwise to dismiss it as unimportant.

Interference with abnormal sphincter-like closure of the outflow tract by ventriculomyotomy appears likely to be important, but possibly all four, or other as yet undefined mechanisms, may be responsible for improvement following operation.

In considering the possibility of abnormal conduction pathways, it is of interest to note that the hypothesis of a genetically determined abnormality of inotropic catecholamine action on the outflow tract of the left ventricle (Goodwin, 1964; Goodwin et al., 1964) has received some support from the work of Dr. Everson Pearse (Pearse, 1964) who has found an excess of adrenergic-type fibres in the resected portions of outflow tract muscle. Interruption of these fibres by deep incision and the removal of even small amounts of them might, therefore, be of importance.

From consideration of the angiographic and pathological appearances of the heart in hypertrophic obstructive cardiomyopathy it appears clear that this is a disorder in which there is widespread disorganization of the heart muscle, and that surgical treatment is most unlikely to effect 
any radical cure of the condition. Surgery, should, in our view, be regarded as a method of limited (but none the less important) value in the treatment of patients with severe obstruction, who, by virtue of symptoms of syncope and angina and appreciable outflow tract obstruction, are in danger of sudden death or are severely and distressingly incapacitated. It should not be employed in patients with milder forms of the disease, in those with impairment of ventricular filling rather than outflow obstruction, or in those in whom severe obstruction is absent at rest and not produced by ectopic beats, exercise, or provocation with inotropic or other drugs.

It is also well to bear in mind that spontaneous reduction in outflow obstruction may occur, as has been the case in one of our patients reported in 1960 (Goodwin et al., 1960, Case 2), who, without specific treatment, has now dramatically lost all evidence of obstruction both clinically and on hæmodynamic testing.

We are, therefore, now directing our efforts to elucidating further the underlying causes of the disease, and investigating the effect of $\beta$-adrenergic blockade, myocardial catecholamine depletion, blood volume expansion, and peripheral vasoconstriction by means of drugs, reserving operation for the patients who fail to respond to medical measures and who are thought to be in grave danger of sudden death.

We do not consider obstruction to right ventricular outflow, which is present in most patients, to be a contraindication to operation, for our drug studies have shown that the characteristic changes in outflow tract gradients, which occur in the left ventricle, cannot be produced in the right ventricle, and we believe that the obstruction is thus secondary to the massive septum and hypertrophied ventricular wall (Goodwin et al., 1964).

\section{SUMMARY}

The results of resection of the obstructing muscle and deep incision (ventriculomyotomy) of the left ventricular outflow tract are described in 12 patients with hypertrophic obstructive cardiomyopathy.

The indications were severe symptoms of angina, or syncope, with or without dyspnœa. The diagnosis was confirmed by clinical examination, left ventricular angiocardiography, and by the demonstration of a systolic gradient across the left ventricular outflow tract of at least $30 \mathrm{~mm}$. $\mathrm{Hg}$ at rest, or after provocation with isoprenaline.

Of the 12 patients, 9 were symptomatically improved; 3 strikingly, 2 considerably, 2 moderately, and 2 slightly; 3 patients died, 1 of a disruption of the aortic wall and 2 from complete heart block.

The 9 patients have been followed from 6 months to 5 years, and post-operative hæmodynamic studies have been made in the 7 who were available for study. These investigations revealed a reduction in outflow gradient in 5 and an increase in 2.

Symptomatic and objective evidence of improvement did not always coincide, and the reasons for this are discussed. The ways in which the operation may produce benefit are debated and it is concluded that the most important effect is probably the deep incision of the outflow tract. Removal of obstructing muscle, and the creation of left bundle-branch block may also play a part. The possible role of pericardial incision is at present under investigation.

Though the operation does not produce any radical cure of the condition, it appears to have a place in the treatment of hypertrophic obstructive cardiomyopathy; it should be reserved for patients with severe disabling symptoms (especially angina and syncope) who are in danger of sudden death, and who show clinical, hæmodynamic, and angiocardiographic evidence of obstruction to left ventricular outflow. The importance is stressed of provoking a gradient if none exists at rest in assessing a patient for operation, and it is considered that operation is contraindicated unless a gradient exists at rest or after provocation with isoprenaline however sinister the symptoms.

The possibilities of medical treatment are discussed, and it is pointed out that the condition may rarely improve spontaneously. 
We are grateful to all our colleagues who have kindly referred patients for diagnosis and treatment, and to the Nursing and Radiographic staff of the Angiographic and Catheterization Unit for their sustained and valuable help. We owe a great debt to Mr. Gerald Rainbow and his cardiological technical staff for their skilled assistance.

Miss Sweetland kindly typed the paper, and the Department of Medical Illustration and Mrs. P. Smy provided the illustrations.

\section{REFERENCES}

Bentall, H. H. (1964). The technique of operation for obstructive cardiomyopathy. In Ciba Foundation Symposium: Cardiomyopathies, ed. G. E. W. Wolstenholme and M. O'Connor, p. 272. Churchill, London.

Björk, V. O., Hultquist, G., and Lodin, H. (1961). Sub-aortic stenosis produced by an abnormally placed anterior mitral leaflet. J. thorac. cardiovasc. Surg., 41, 659.

Braunwald, E., and Ebert, P. A. (1962). Hemodynamic alterations in idiopathic hypertrophic subaortic stenosis iuduced by sympathomimetic drugs. Amer. J. Cardiol., 10, 489.

-, Morrow, A. G., Cornell, W. P., Aygen, M. M., and Hilbish, T. F. (1960). Idiopathic hypertrophic subaortic stenosis. Amer. J. Med., $29,924$.

Brock, R. C. (1957). Functional obstruction of the left ventricle. Guy's Hosp. Rep., $106,221$.

Cleland, W. P. (1964a). The surgical management of obstructive cardiomyopathy. Proc. roy. Soc. Med., $57,446$. (1964b). The results of surgical treatment of hypertrophic obstructive cardiomyopathy. In Ciba Foundation Symposium:Myocardiopathies, p. 276.

Cohen, J., Effat, H., Goodwin, J. F., Oakley, C. M., and Steiner, R. E. (1964). Hypertrophic obstructive cardiomyopathy. Brit. Heart J., 26, 16.

Dobell, A. R. C., and Scott, J. H. (1964). Hypertrophic subaortic stenosis: Evolution of a surgical technique. J. thorac. cardiovasc. Surg., 47, 26.

Goodwin, J. F. (1964). Cardiac function in primary myocardial disorders. Brit. med. J., 1, 1527 and 1595.

- Hollman, A., Cleland, W. P., and Teare, D. (1960). Obstructive cardiomyopathy simulating aortic stenosis. Brit. Heart J., $22,403$.

- Shah, P. M., Oakley, C. M., Cohen, J., Yipintsoi, T., and Pocock, W. (1964). The clinical pharmacology of hypertrophic obstructive cardiomyopathy. In Ciba Foundation Symposium: Cardiomyopathies, p. 189.

Hollister, R. M., and Goodwin, J. F. (1963). The electrocardiogram in cardiomyopathy. Brit. Heart J., $25,357$.

Kirklin, J. W., and Ellis, F. H., Jr. (1961). Surgical relief of diffuse subvalvular aortic stenosis. Circulation, $24,739$.

Kittle, C. F., Reed, W. A., and Crockett, J. E. (1964). Infundibulectomy for subaortic hypertrophic stenosis. Circulation, 29, Suppl. 4, p. 119.

Morrow, A. G., and Brockenbrough, E. C. (1961). Surgical treatment of idiopathic hypertrophic subaortic stenosis. Ann. Surg., 154, 181.

Pearse, A. G. E. (1964). The histochemistry and electron microscopy of obstructive cardiomyopathy. In Ciba Foundation Symposium: Cardiomyopathies, p. 132.

Swan, H. (1964). Subaortic muscular stenosis: A new surgical technique for repair. J. thorac. cardiovasc. Surg., 47,681 .

Teare, D. (1958). Asymmetrical hypertrophy of the heart in young adults. Brit. Heart J., $20,1$.

Trimble, A. S., Bigelow, W. G., Wigle, E. D., and Chrysohou, A. (1964). Simple and effective surgical approach to muscular subaortic stenosis. Circulation, 29, Suppl. 4, p. 125.

Wigle, E. D., Chrysohou, A., and Bigelow, W. G. (1963). Results of ventriculomyotomy in muscular subaortic stenosis. Amer. J. Cardiol., 11, 572.

- Heimbecker, R. O., and Gunton, R. W. (1962). Idiopathic ventricular septal hypertrophy causing muscular subaortic stenosis. Circulation, 26, 325.

\section{AdDENDUM}

Since this paper was written 4 further patients have been operated on. The first, a lady of 37 years, with an extremely severe form of the disease, died 5 days after operation in ventricular fibrillation, but the second, a man of 25 years, has excellent clinical evidence of relief of obstruction one month after operation, as have the third and fourth, a woman of 28 years and a man of 41 years. These patients have been operated on too recently for post-operative studies to have been made. 